\title{
Total inotrope exposure score: an extension of the vasoactive inotrope score
}

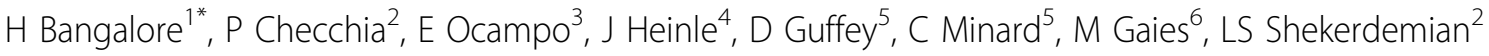 \\ From ESICM LIVES 2015 \\ Berlin, Germany. 3-7 October 2015
}

\section{Intr}

To incorporate advances in documentation with computerised Electronic Medical Record systems, enable ease of calculation, and provide a single score for vasoactive support after cardiac surgery in children across all ages, we explore a modification of the VIS, which is the Total Inotrope Exposure Score (TIES).

\section{Objectives}

To study the performance of the TIES as compared to the VIS.

\section{Methods}

A single-centred retrospective study was conducted in children undergoing cardiac surgery with Cardiopulmonary bypass (CBP) between September 2010 and May 2011. The average and maximum VIS at 24 and 48 hours (VIS $_{\text {avg } 24, ~}$ VIS $_{\max } 24, \mathrm{VIS}_{\max } 48, \mathrm{VIS}_{\text {avg }} 48$ ) and TIES were calculated. The performance of these scores to predict primary clinical outcome- either death, Cardiopulmonary resuscitation, extra-corporeal membrane oxygenation (ECMO) before hospital discharge and secondary outcomes-prolonged length of invasive mechanical ventilation, length of intensive care unit(ICU) stay and hospital stay were calculated.

\section{Results}

167 separate admissions included $37(22.2 \%)$ neonates and $65(41.3 \%)$ infants with a mean age of 2.9 (6.0) years. Twenty percent had higher complexity operations with a RACHS-1 category of 4-6.

The TIES predicted the primary outcome (6 of 167 cases) with an AUC $0.92(0.86,0.97)$. The unadjusted odds ratio for a poor outcome was OR $42(4.8,369.6)]$.

${ }^{1}$ Great Ormond Street Hospital, Paediatric Intensive Care Unit, London, United Kingdom

Full list of author information is available at the end of the article
The TIES score best predicted prolonged ventilation with an AUC of $0.88(0.81,0.95)$ compared to $\mathrm{VIS}_{\text {avg }} 24$ $0.73(0.64,0.82)[\mathrm{p}=0.0001], \mathrm{VIS}_{\max } 24-0.74(0.66,0.83)$ $[\mathrm{p}=0.0011], \mathrm{VIS}_{\text {avg }} 48-0.74$

$(0.65,0.82)$ [p $<0.0001], \mathrm{VIS}_{\max } 48-0.67(0.58,0.77)$ [p $<0.001]$. TIES was the best predictor of prolonged mechanical ventilation with an adjusted OR of 13.6 (3.9, 47.8) at a cut off of 14.7. None of the other scores significantly predicted prolonged ventilation after adjusting for covariates in a multiple regression. The TIES score best predicted freedom from mechanical ventilation with an adjusted-hazard ratio of Cox proportional hazard model of $0.97(0.96,0.99)$ [ $p=0.01]$.

Similarly, the adjusted odds of a prolonged CVICU stay was predicted by the TIES score with an OR of $\geq 12.7$ $(3.51,45.7)$ at a cut off of 14.7. The other scores which predicted a prolonged CVICU stay were - $\mathrm{VIS}_{\text {avg }} 24 \geq 4.5$ OR $4.3(1.3,14.1)$; $\mathrm{VIS}_{\max } 24 \geq 4.8$ OR $7.3(2.2,24.2)$; VISavg48 $\geq 3.1$ OR 3.5(1.1, 10.7).

The odds of a prolonged hospital stay were 4 (1.37, $11.66)$ and $12.2(2.5,60.9)$ for $\operatorname{VIS}_{\text {avg }} 48$ and TIES at cut offs of 3.1 and 14.7 respectively. The TIES score best predicted discharge from the ICU and hospital with an adjusted Hazard Ratio of 0.96(0.94, 0.98) [p < 0.001] and $0.98(0.96,0.99)[\mathrm{p}<0.024]$.

\section{Conclusions}

The TIES score performed well and warrants prospective validation across larger numbers of patients, and across institutions.

\footnotetext{
Authors' details

${ }^{1}$ Great Ormond Street Hospital, Paediatric Intensive Care Unit, London, United Kingdom. ${ }^{2}$ Texas Childrens Hospital, Pediatric Critical Care, Houston, TX, United States. ${ }^{3}$ Texas Childrens Hospital, Pediatric Cardiology, Houston, TX, United States. ${ }^{4} T e x a s$ Childrens Hospital, Pediatric Congenital Heart Surgery, Houston, TX, United States. ${ }^{5}$ Baylor College of Medicine,
} 
Published: 1 October 2015

doi:10.1186/2197-425X-3-S1-A211

Cite this article as: Bangalore et al:: Total inotrope exposure score: an extension of the vasoactive inotrope score. Intensive Care Medicine Experimental 2015 3(Suppl 1):A211.

\section{Submit your manuscript to a SpringerOpen ${ }^{\mathcal{O}}$ journal and benefit from:}

- Convenient online submission

- Rigorous peer review

- Immediate publication on acceptance

- Open access: articles freely available online

- High visibility within the field

- Retaining the copyright to your article

Submit your next manuscript at $\gg$ springeropen.com 